\title{
Life and Operating Range Extension of the BPT-4000 Qualification Model Hall Thruster
}

\author{
Ben Welander ${ }^{*}$, Christian Carpenter ${ }^{\dagger}$ and Kristi de Grys ${ }^{\ddagger}$ \\ Aerojet General, Redmond, WA, 98073 \\ Richard R. Hofer ${ }^{\S}$ and Thomas M. Randolph ${ }^{* *}$ \\ Jet Propulsion Laboratory, California Institute of Technology, Pasadena, CA, 91109 \\ and \\ David H. Manzella ${ }^{\dagger+}$ \\ NASA Glenn Research Center, Cleveland, OH,44135
}

\begin{abstract}
Following completion of the 5,600 hour qualification life test of the BPT-4000 $4.5 \mathrm{~kW}$ Hall Thruster Propulsion System, NASA and Aerojet have undertaken efforts to extend the qualified operating range and lifetime of the thruster to support a wider range of NASA missions. The system was originally designed for orbit raising and stationkeeping applications on military and commercial geostationary satellites. As such, it was designed to operate over a range of power levels from 3 to $4.5 \mathrm{~kW}$. Studies of robotic exploration applications have shown that the cost savings provided by utilizing commercial technology that can operate over a wider range of power levels provides significant mission benefits. The testing reported on here shows that the $4.5 \mathrm{~kW}$ thruster as designed has the capability to operate efficiently down to power levels as low as $1 \mathrm{~kW}$. At the time of writing, the BPT4000 qualification thruster and cathode have accumulated over 400 hours of operation between $1 \mathrm{~kW}-2 \mathrm{~kW}$ with an additional 600 hours currently planned. The thruster has demonstrated no issues with longer duration operation at low power.
\end{abstract}

\section{Nomenclature}

$I_{d} \quad=$ discharge current

$I_{S P} \quad=$ specific impulse

$P_{d} \quad=$ discharge power

$T \quad=$ thrust

$V_{d} \quad=$ discharge voltage

\section{Introduction}

$\mathrm{H}$ all thrusters have provided station-keeping on Russian spacecraft for decades and have more recently been demonstrated on Western geosynchronous (GEO) communications satellites ${ }^{1,2}$. Additionally, SMART-1 successfully demonstrated the use of Hall thrusters as primary propulsion systems for orbit transfer and capture on a science mission ${ }^{3}$. As Hall thrusters continue to gain acceptance in the commercial marketplace, NASA has begun considering them more broadly based on their lower system cost compared to other electric propulsion systems with

\footnotetext{
${ }^{*}$ Project Engineer, Systems and Technology Development, P.O. Box 97009, AIAA Member.

${ }^{\dagger}$ Senior Project Engineer, Systems and Technology Development, P.O. Box 97009, AIAA Member.

${ }^{\ddagger}$ Manager of Programs, Systems and Technology Development, P.O. Box 97009, AIAA Member.

$\S$ Member of the Technical Staff, Advanced Propulsion Technology Group, Propulsion and Materials Engineering Section, Member AIAA.

${ }^{* *}$ Senior Engineer, Advanced Propulsion Technology Group, Propulsion and Materials Engineering Section, AIAA Senior Member.

${ }^{+\dagger}$ Electrical Engineer, Electrical Propulsion Branch, 21000 Brookpark Rd., M.S. 301-3, AIAA Member.
} 
similar performance. JPL has recently conducted studies for cost-capped science missions such as those conducted under the NASA Discovery Program and found that several missions could benefit from a commercially-available electric propulsion system with wide power and throttling capabilities ${ }^{4}$. NASA GRC and Aerojet have over the past several years been developing Hall thruster technology to provide enhanced throttle range and higher specific impulse capability than state-of-the-art Hall thrusters to maximize interplanetary mission benefits ${ }^{5}$.

The BPT-4000 Hall thruster propulsion system (HTPS) was developed through a joint effort between Lockheed Martin Space Systems and Aerojet-General as a $4.5 \mathrm{~kW}$ electric propulsion system for GEO satellite applications. In 2005, Aerojet successfully completed the planned qualification of this system ${ }^{6,7}$. During qualification, the BPT4000 demonstrated $>6700$ starts, $>5800$ hours of operation, $>4.9 \times 10^{6} \mathrm{~N}$-s of total impulse, and $>250 \mathrm{~kg}$ of xenon throughput. Test firings varied in duration from 5 minutes to over 200 hours, covered a power range from 3 to 4.5 $\mathrm{kW}$, and discharge voltages from 300 to $400 \mathrm{~V}$.

After firing for 5800 hours, the BPT-4000 operated more efficiently than during any previous period and erosion was slowed significantly ${ }^{7}$. Measurements of the insulator ring erosion and the cathode health showed the thruster had significantly more life capability. Figure 1 displays the thruster condition at the end of commercial qualification (EOT). The image on the left shows the extent of erosion to the thruster downstream surfaces and cathode keeper shell after 23 megawatt-hours (i.e., after 5800 hours). Although the erosion of the insulator rings is extensive, the dielectric coating on the pole pieces still retains about half of its original thickness near the channel. Deposition has been removed from cathode keeper surfaces with direct view of the annulus but the shell has no signs of degradation.

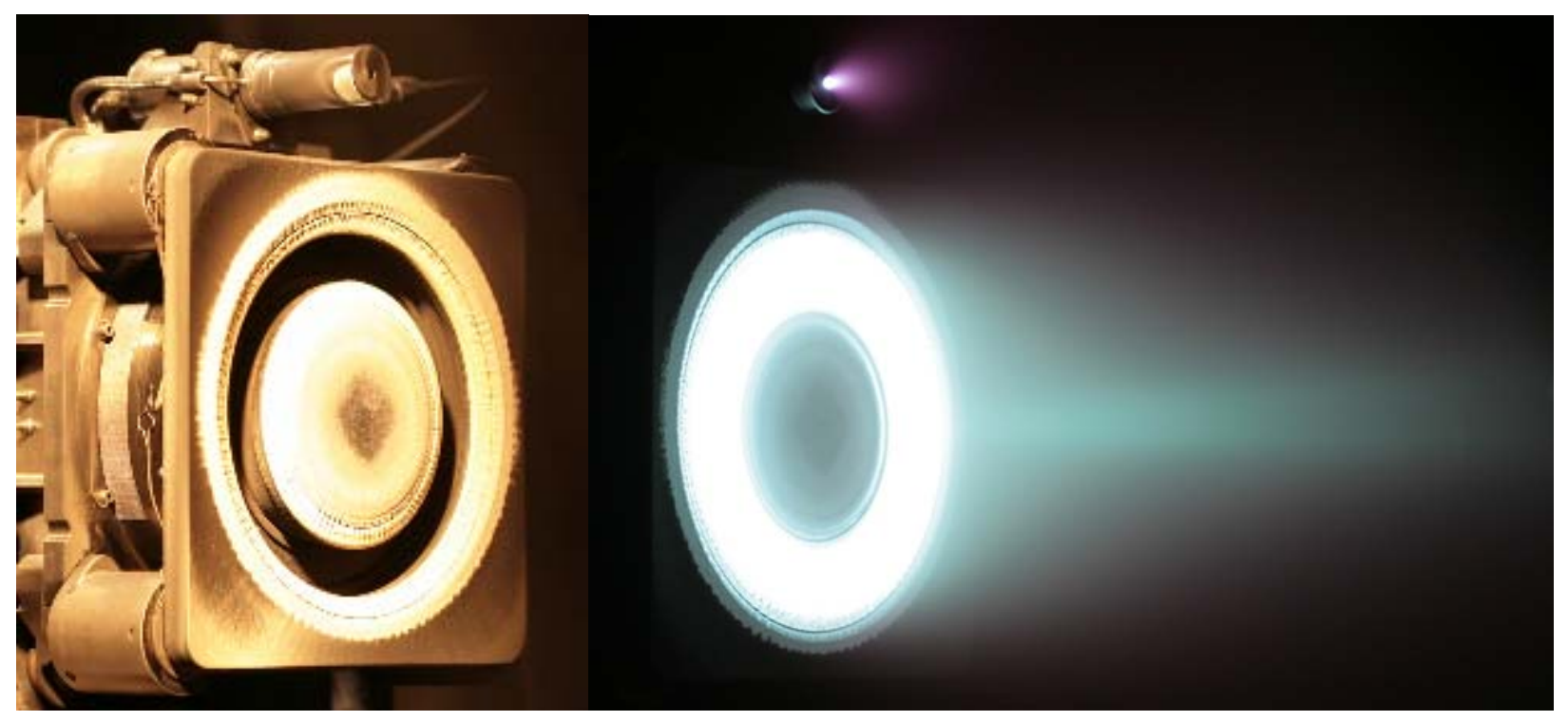

Figure 1. The BPT-4000 showing 5800 hours of wear (left) and $1 \mathrm{~kW}$ operation (right).

NASA has funded Aerojet to assess the performance of the BPT-4000 down to the $1 \mathrm{~kW}$ power level and demonstrate extended duration operation to characterize erosion rates and cathode operation at low power. This paper documents this effort. Sections II and III describe the objectives of the qualification extension and provide a brief description of the facility and setup. Subsequent sections present results of blow-down testing, low-power performance of the thruster and PPU and discuss the first 400 hours of low-power operation. 


\section{Test Objectives}

NASA and Aerojet partnered to conduct additional qualification that stretched both the lifetime and the throttle range of the thruster. The qualification extension consists of three sections including a blow-down test, performance characterization, and a life test extension (LTE). The objective of the blow-down test is to demonstrate the capability of the HTPS to operate in an unregulated pressure mode. The objectives of thruster characterizations are to measure erosion and map the performance of the thruster between 1 and $2 \mathrm{~kW}$. The objective of the LTE is to demonstrate sustained operation at low power and extend the qualified life of the BPT-4000.

The extended qualification test plan started with a thruster characterization followed by blow-down testing. After quantifying low-power performance, the thruster entered the first of two 500-hour life test blocks of sustained low-power operation. The test plan was specified to ensure that testing was conducted to maximize data return with the lowest possible risk to the test hardware. The first 500-hour test block consists of five segments at currents of $5 \mathrm{~A}$, conducted at successively lower powers as shown in Table 1. The intent of each segment is to demonstrate stable, sustained operation at powers as low as $1 \mathrm{~kW}$. The thruster characterization is repeated before starting the second test block, where the thruster will accumulate hours exclusively at $1.5 \mathrm{~kW}-300 \mathrm{~V}$.

\begin{tabular}{|c|c|c|}
\hline$P_{d}$ & Segment Cycles & Total Hours \\
\hline $2.00 \mathrm{~kW}$ & 4 & 100 \\
\hline $1.75 \mathrm{~kW}$ & 4 & 200 \\
\hline $1.50 \mathrm{~kW}$ & 4 & 300 \\
\hline $1.25 \mathrm{~kW}$ & 4 & 400 \\
\hline $1.00 \mathrm{~kW}$ & 4 & 500 \\
\hline
\end{tabular}

Table 1. Block 1 of the BPT-4000 life test extension.

\section{Facility and Test Setup}

Both the original life test and the low-power LTE were conducted in Aerojet's Chamber 2 facility, which is described in detail in previous publications ${ }^{8}$. The BPT-4000 sits on an inverted pendulum thrust stand inside a 2.1-m diameter by 7.2-m stainless steel vacuum chamber. Throughout qualification and the life test extension, a qualification model XFC delivered propellant to the BPT-4000 and a development model PPU powered both the thruster and the XFC. The flight model PPU has upgraded components for improved tolerance to thermal variations, flash X-ray, and electromagnetic interference but it is electrically and functionally equivalent to the unit used to qualify the BPT-4000.

\section{Blow-down Testing}

During nominal operation, the XFC receives propellant at feed pressures between 34 and 40 psia (235-275 kPa). In order to minimize ullage propellant, a test was designed to demonstrate operation at lower feed pressures. The thruster was started normally at $4.5 \mathrm{~kW}-400 \mathrm{~V}$ with 38 psia feed pressure. After reaching steady state, the xenon supply bottle was closed and the feed pressure was allowed to drop. To slow the rate of pressure decline, a volume was added to the feed system and filled with xenon at the nominal feed pressure.

During the first several hours of testing, the feed pressure dropped without affecting thruster performance. The mass flow rate and discharge current remained steady because the proportional flow control valve in the XFC gradually opened as commanded by the PPU loop control. As shown in Figure 2, the PFCV reached full open about an hour before test shutdown. After this point, the declining feed pressure began to decrease flow rate. Discharge current followed flow rate until a lower limit of $5 \mathrm{~A}$ was reached and the test was voluntarily terminated. The thruster operated stably down to the $5 \mathrm{~A}$ limit with no increases in discharge current or voltage oscillations. By demonstrating operation at less than $25 \%$ nominal feed pressure, the HTPS can facilitate either a propellant mass savings or extended mission duration.

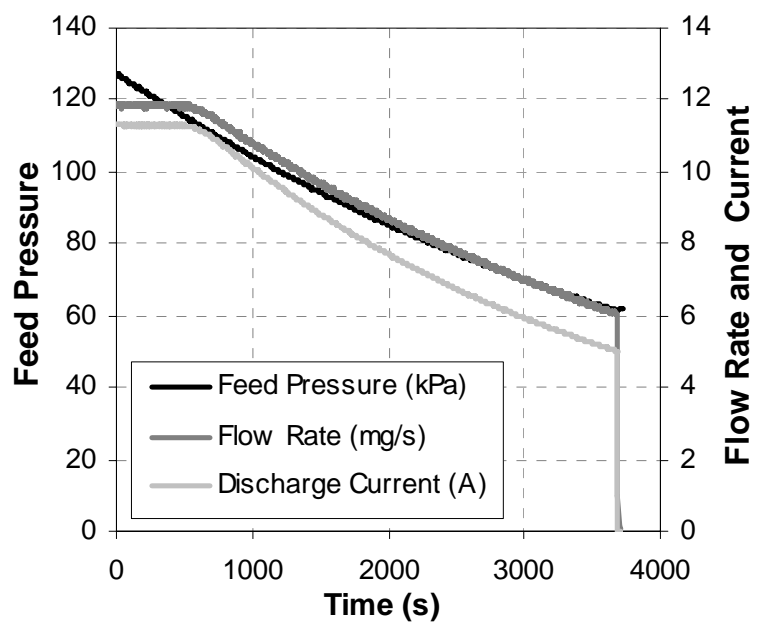

Figure 2. Feed pressure, flow rate and $I_{d}$ during the last hour of blow-down testing. 


\section{BPT-4000 Thruster Performance at Low Power}

After blow-down testing, the BPT-4000 began low-power testing. Starting at $2 \mathrm{~kW}$, the HTPS demonstrated steady operation at successively decreasing power. Performance results from thruster characterizations and the first 400 hours of extended testing are shown in Table 2. Thrust values are the difference between a measurement taken at the end of each cycle and a tare measurement taken one minute after shutdown. Specific impulse includes flow rate to the thruster and cathode and is corrected for the finite chamber pressure.

Figure 3 shows thruster efficiency measurements taken at the end of the BPT-4000 qualification and during the life test extension. Efficiency is calculated using $T$ and $I_{S P}$ calculated above and $P_{d}$. These measurements are graphed along with reported data from the end of the SPT-100 cyclic endurance test ${ }^{9}$ and the PPS-1350-G qualification ${ }^{10}$ for comparison. Although the BPT-4000 was optimized for $4.5 \mathrm{~kW}$, it operates with greater efficiency than the SPT-100 and PPS-1350-G at similar power levels. The graph shows that, while BPT-4000 performance does decrease with power level, the efficiency remains above $50 \%$ for $P_{d}$ as low as $1.25 \mathrm{~kW}$.

\begin{tabular}{|ccc|}
\hline & $\boldsymbol{T}(\mathbf{m N})$ & $\boldsymbol{I}_{\boldsymbol{S P}}(\mathbf{s})$ \\
$4.5 \mathrm{~kW}-400 \mathrm{~V}$ & 254 & 2150 \\
$4.5 \mathrm{~kW}-300 \mathrm{~V}$ & 278 & 1960 \\
$3.0 \mathrm{~kW}-400 \mathrm{~V}$ & 171 & 2010 \\
$3.0 \mathrm{~kW}-300 \mathrm{~V}$ & 190 & 1840 \\
& & \\
$2.00 \mathrm{~kW}-400 \mathrm{~V}$ & 115 & 1860 \\
$1.75 \mathrm{~kW}-350 \mathrm{~V}$ & 107 & 1740 \\
$1.50 \mathrm{~kW}-300 \mathrm{~V}$ & 103 & 1610 \\
$1.25 \mathrm{~kW}-250 \mathrm{~V}$ & 92 & 1440 \\
$1.00 \mathrm{~kW}-200 \mathrm{~V}$ & 79 & 1220 \\
\hline
\end{tabular}

Table 2. Performance map of the BPT-4000.

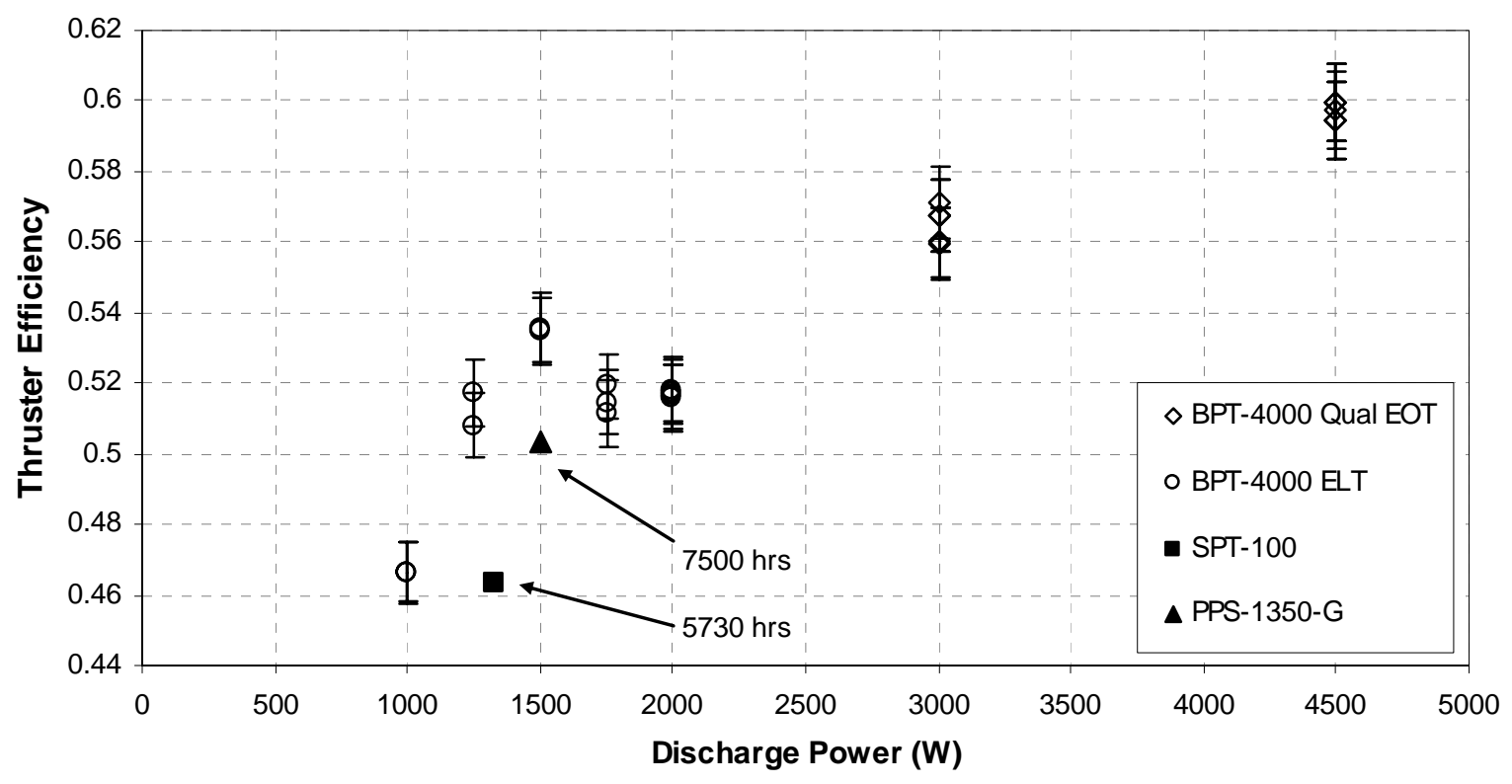

Figure 3. BPT-4000 thruster efficiency vs. discharge power.

\section{System Performance at Low Power}

The LTE also demonstrated operation of the system at lower power levels. The PPU has two 2.5-kW anode supply modules (ASMs) capable of providing the BPT4000 with up to $5 \mathrm{~kW}$ of discharge power. By demonstrating low-power operation on one anode supply module, the HTPS increases the range of missions that it may support. This capability adds increased system efficiency during low power operation and provides risk reduction since a single string HTPS may still be operational if there is a loss of an ASM. All life test extension cycles at $5 \mathrm{~A}$ used a start sequence with only one powered ASM in which the start-up powers never exceeded the nominal operating power levels (Table 1).

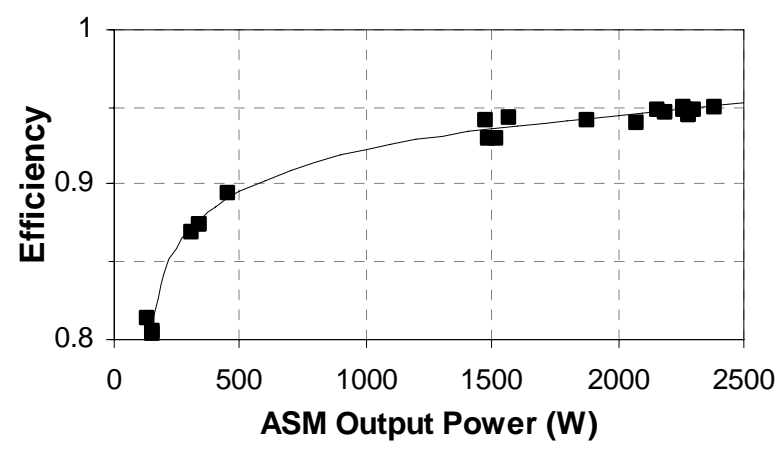

Figure 4. Efficiency of the PPU ASM. 


\section{Health and Stability during Extended Life Testing}

The test program has included operation at lower power levels for given specific impulse than have been previously tested with this engine. Although designed for discharge currents as high as $15 \mathrm{~A}$, the BPT-4000 has operated almost exclusively at 5 A for over 400 hours. The thruster and cathode have operated without stability issues at all power levels tested. Peak-to-peak current $\left(I_{d}\right)$ oscillations were $10+/-3 \mathrm{~A}$ at the end of qualification testing and have remained in this range throughout low power testing. Similarly, voltage oscillation amplitudes measured during the LTE are comparable to those from 3 and $4.5 \mathrm{~kW}$ operations. Cathode ignition voltages have remained below $20 \mathrm{~V}$ and temperatures have remained nominal. The cathode floating potential has been less than 14 $\mathrm{V}$ with respect to ground and stable throughout testing. This demonstrates both excellent cathode health and cathode coupling to the thruster despite the low flow rate, current, and voltage. No appreciable wear has been measured suggesting that low-power operation does not significantly change erosion rates, but detailed analysis of erosion data is still pending. When the life test extension is complete, the BPT-4000 will demonstrate a throughput capability greater than $285 \mathrm{~kg}$ and a total impulse greater than $5.4 \times 10^{6} \mathrm{~N}-\mathrm{s}$.

\section{Conclusion}

Aerojet's commercially available BPT-4000 Hall thruster has demonstrated increased life and an expanded operating range as part of a life test extension funded by NASA. Although designed for $4.5-\mathrm{kW}$ operation, the thruster's performance exceeds $50 \%$ for discharge powers as low as $1.25 \mathrm{~kW}$. At the time of writing, the qualification thruster and cathode have accumulated over 400 hours of stable, low-power operation. When the LTE is completed, the BPT-4000 will have accumulated $5.4 \times 10^{6} \mathrm{~N}$-s of impulse, processed $285 \mathrm{~kg}$ of xenon propellant and operated for more than 1000 hours below $2 \mathrm{~kW}$. Future work includes characterizing erosion rates at low power for model correlation and more accurate predictions of thruster life. The lower power limit for the LTE was arbitrarily set at $1 \mathrm{~kW}$. Based on the positive test results, additional BPT-4000 testing may be performed to demonstrate both extended life and operational capability below $1 \mathrm{~kW}$.

\section{Acknowledgments}

Work performed at Aerojet is supported by the NASA Glenn Research Center under contract NNC04CB14C. The authors thank Mr. Doug Ley for his support of the testing described in this paper. The authors gratefully acknowledge Mr. Robert Kay for providing the PPU efficiency data and insight.

\section{References}

${ }^{1}$ Day, M., Naslennikov, N., Randolph, T., and Rogers, W., “SPT-100 Subsystem Qualification Status,” AIAA-95-2666, 31 ${ }^{\text {st }}$ AIAA/ASME/SAE/ASEE Joint Propulsion Conference, San Diego, CA, July 10-12, 1995.

${ }^{2}$ Duchemin, O., Cornu, N., Darnon, F., and Estublier, D., "Endurance Test at High Voltage of the PPSX000 Hall-Effect Thruster," AIAA-2005-4050, 41 $1^{\text {st }}$ AIAA/ASME/SAE/ASEE Joint Propulsion Conference and Exhibit, Tucson, AZ, July 10-13, 2005.

${ }^{3}$ Koppel, C. R. and Estublier, D., “The SMART-1 Hall Effect Thruster Around the Moon: In Flight Experience,” IEPC-2005119, $29^{\text {th }}$ International Electric Propulsion Conference, Princeton University, October 31-November 4, 2005.

${ }^{4}$ Hofer, R. R., Randolph, T. M., Oh, D. Y., Snyder, J. S., de Grys, K. H., "Evaluation of a 4.5 kW Commercial Hall Thruster System for NASA Science Missions," AIAA-2006-4469, 42nd Joint Propulsion Conference, Sacramento, CA, July 9-12, 2006.

${ }^{5}$ Manzella, D., Oh, D., Aadland, R., "Hall Thruster Technology for NASA Science Missions," AIAA-2005-3675, 41 ${ }^{\text {st }}$ AIAA/ASME/SAE/ASEE Joint Propulsion Conference and Exhibit, Tucson, AZ, July 10-13, 2005.

${ }^{6}$ de Grys, K., Welander, B., Dimicco, J., Wenzel, S., Kay, B., Kayms, V., Paisley, J., "4.5 kW Hall Thruster System Qualification Status,” AIAA-2005-3682, 41 ${ }^{\text {st }}$ AIAA/ASME/SAE/ASEE Joint Propulsion Conference and Exhibit, Tucson, AZ, July 10-13, 2005.

7Welander, B. and de Grys, K., “Completion of the BPT-4000 Hall Thruster Qualification,” 53rd JANNAF Propulsion Meeting / 2nd Liquid Propulsion Subcommittee Meeting / $1^{\text {st }}$ Spacecraft Propulsion Subcommittee Meeting, Monterey, CA, December 5-8, 2005.

${ }^{8}$ de Grys, K., Meckel, N., Callis, G., Greisen, D., Hoskins, A., King, D., Wilson, F., Werthman, L., Kayms, V., "Development and Testing of a 4500 Watt Flight Type Hall Thruster and Cathode," IEPC-01-011, 27 ${ }^{\text {th }}$ International Electric Propulsion Conference, Pasadena, CA, Octobter 15-19, 2001.

${ }^{9}$ Garner, C. E., Brophy, J. R., Polk, J. E., and Pless, L. C., “A 5730-Hr Cyclic Endurance Test of the SPT-100,” AIAA-952667, $31^{\text {st }}$ AIAA/ASME/SAE/ASEE Joint Propulsion Conference, San Diego, CA, July 10-12, 1995.

${ }^{10}$ Marchandise, F., Biron, J., Gambon, M., Cornu, N., Darnon, F., and Estublier, D., “The PPS 1350 Qualification Demonstration 7500h on Ground, about 5000h in Flight,” IEPC-2005-209, $29^{\text {th }}$ International Electric Propulsion Conference, Princeton University, October 31-November 4, 2005. 